\title{
Erratum to: Cryptic mitochondrial lineages in the widespread pycnogonid Colossendeis megalonyx Hoek, 1881 from Antarctic and Subantarctic waters
}

\author{
Kathrin Krabbe - Florian Leese - Christoph Mayer • \\ Ralph Tollrian $\cdot$ Christoph Held
}

Published online: 4 March 2010

(C) Springer-Verlag 2010

\section{Erratum to: Polar Biol}

DOI 10.1007/s00300-009-0703-5

The statement in the Introduction reading "For Colossendeis species this egg carrying behaviour is also common (e.g. Lehmann et al. 2007)" is incorrect. In fact, still nothing is known about the egg deposition for Colossendeis.

The online version of the original article can be found under doi:10.1007/s00300-009-0703-5.

K. Krabbe $\cdot$ F. Leese $(\bowtie) \cdot$ C. Mayer $\cdot$ R. Tollrian Lehrstuhl für Evolutionsökologie und Biodiversität der Tiere, Ruhr-University Bochum, Bochum 44801, Germany e-mail: florian.leese@rub.de

C. Held Alfred-Wegener-Institut für Polar- und Meeresforschung, Postfach 12 0161, 27515, Bremerhaven, Germany 